\title{
Bacterial 16S rRNA/rDNA Profiling in the Liquid Phase of Human Saliva
}

\author{
F. Gu ${ }^{1, \#}$, Y. $\mathrm{Li}^{3}$, C. Zhou ${ }^{3}$, D.T.W. Wong ${ }^{1}$, C.M. $\mathrm{Ho}^{2}$, F. Qi ${ }^{1}$ and W. Shi ${ }^{1, *}$
}

${ }^{1}$ Division of Oral Biology and Medicine, UCLA School of Dentistry, Los Angeles, California 90095; ${ }^{2}$ Department of Engineering, UCLA Henry Samueli School of Engineering and Applied Sciences, Los Angeles, California 90095; ${ }^{3}$ Department of Basic Science and Craniofacial Biology, New York University College of Dentistry, New York, NY 10010 and ${ }^{\#}$ Current address: School of Dentistry, University of North Carolina, Chapel Hill, NC27599, USA

\begin{abstract}
Human saliva can be separated by centrifugation into cell pellet and cell-free supernatant, which are called cellular phase and liquid phase in this study. While it is well documented that the cellular phase of saliva contains hundreds of oral bacteria species, little is known whether the liquid phase of saliva contains any information related to oral microbiota. In this study, we analyzed the bacterial nucleic acid contents of the liquid phase of saliva. Using primers universal to most eubacterial 16S rDNA, we detected large amounts of bacterial 16S rRNA and rDNA in the cell-free phase of saliva. Random sequencing analysis of forty PCR amplicons from the cell-free phase of saliva led to 15 operational taxonomic unit (OTU) groups. Furthermore, using denaturing gradient gel electrophoresis (DGGE), we compared 16S rRNA/rDNA profiles derived from liquid phases and cellular phases of saliva samples, and found positive correlations (Pearson Correlation=0.822, $P<0.001$ ) between these sample groups. These findings indicate that the liquid phase of saliva contains numerous bacterial $16 \mathrm{~S}$ rRNA/rDNA molecules that have correlations with bacteria existing in the cellular phase.
\end{abstract}

Key Words: Saliva, oral bacteria, 16S rRNA, 16S rDNA, DGGE.

\section{INTRODUCTION}

The oral cavity harbors over 700 microbial species [1,2]. While the majority of them are normal/commensal bacteria, some of them are opportunistic pathogens responsible for the development of oral microbial infectious diseases such as dental caries and periodontitis [3]. Saliva as an oral circulating fluid is heavily laden with bacteria $\left(10^{8}-10^{9} \mathrm{cfu} / \mathrm{mL}\right)$ [4]. These salivary bacteria reflect the oral microbiota composition and could serve as an indicator of the health and disease status of oral cavity. For example, salivary bacteria counts have often been used for caries risk assessment [5-7].

Various techniques have been developed to obtain the counts of salivary pathogenic bacteria. As the advances in understanding of bacterial genetics, nucleic acid based detection techniques, including PCR based detection method [814] and the "checkerboard" method [15-18], are starting to enjoy more applications. Most nucleic acid based detection methods rely on analyzing bacterial 16S rDNA or rRNA, which has high specificity and sensitivity. Previously, all 16S rDNA or rRNA based saliva studies had been performed using cell pellets derived from whole saliva via centrifugation or filtration (called cellular phase in this study). The subsequent analysis involved bacterial lysis, which may attract some critics that certain bacterial species may be more susceptible to the lysis method than the others. Recently, there have been reports that cell-free supernatants of human saliva after centrifugation or filtration (called liquid phase of saliva in this study) contained extensive viral and human

*Address correspondence to this author at the UCLA School of Dentistry, 10833 Le Conte Avenue, Los Angeles, CA 90095, USA; Tel: 310-8258356; Fax: 310-794-7109; E-mail: Wenyuan@ucla.edu
DNAs and RNAs [19-21], which could be detected by some sensitive microelectromechanical systems (MEMS) [22]. These findings prompted us to initiate this study to examine the existence of bacterial 16S rDNA/rRNA in the liquid phase of saliva and their possible correlations with intact bacterial cells in saliva.

\section{MATERIALS AND METHODS}

\section{Saliva Collection and Processing}

Three male and six female healthy adults aged between 20 to 40 years were recruited (University of California at Los Angeles IRB \#04-10-016-01). One milliliter of nonstimulated whole saliva sample was collected from each individual by asking the subject to expectorate into a sterile disposable plastic cup. The saliva samples were then centrifuged at $13.2 \times 1000 \mathrm{rpm}$ for $30 \mathrm{~min}$. The supernatant was filtered through a $0.2 \mu \mathrm{m}$ filter (Millipore Inc., Billerica, MA). Both the cell pellet (cellular phase) and the supernatant (liquid phase) of the whole saliva were processed for nucleic acid isolation.

\section{Nucleic Acid Isolation}

To isolate nucleic acids from the cellular phase of saliva, cell pellets were re-suspended in $0.5 \mathrm{ml}$ TE buffer (TrisEDTA, pH7) containing $0.1 \mathrm{ml}$ phenol. The resuspended cells were mechanically disrupted by using a homogenizer for $2 \mathrm{~min}$ at $4^{\circ} \mathrm{C}$. Cell debris was removed by centrifugation, and the supernatant was used to extract the nucleic acids. Proteins within the supernatant were removed with phenolchloroform extraction and the total nucleic acids within the supernatant were precipitated by isopropanol in the presence of $0.3 \mathrm{M}$ sodium acetate, air dried, and resuspended in $50 \mu \mathrm{l}$ 
of TE buffer. To isolate nucleic acids from the liquid phase of saliva, the filtrate was extracted once with phenolchloroform to remove protein components, and the supernatant was precipitated with isopropanol in the presence of $0.3 \mathrm{M}$ sodium acetate. The pellet was washed with $70 \%$ ethanol, air-dried, and resuspended in $20 \mu 1 \mathrm{TE}$ buffer.

\section{Detection of Bacterial 16S rRNA and rDNA}

PCR and RT-PCR assays were used to detect bacterial 16S rDNA and rRNA in the cellular and liquid phases of saliva, respectively. For detection of $16 \mathrm{~S}$ rDNA, the nucleic acid preparations were directly used as templates for PCR reactions without reverse transcription. For detection of $16 \mathrm{~S}$ rRNA, the nucleic acid preparations were reverse transcribed to cDNA using Superscript II Reverse Transcriptase (RT) (Invitrogen, Carlsbad, CA) and random hexamer primers (Invitrogen) following the manufacture's instruction before served as templates for PCR reactions. The rRNA profiles were obtained via comparison between samples treated with PCR and RT-PCR.

The primer pair BA968F/BA1401R (5'-AACGCGAAG AACCTTAC -3'/ 5'-CGGTGTGTACAAGACCC -3') [23] was used to detect $16 \mathrm{~S}$ rDNA/rRNA. The PCR reaction mixture $(50 \mu \mathrm{l})$ contained 0.1 to $1 \mathrm{ng}$ of template DNA/ cDNA, $200 \mu \mathrm{M}$ of each dNTP, $40 \mathrm{pM}$ of each primer, 4.0 $\mathrm{mM}$ of $\mathrm{MgCl}_{2}, 5 \mu \mathrm{L}$ of $10 \times$ PCR buffer II, and $2.5 \mathrm{U}$ of Taq DNA polymerase (PE Applied Biosystems). The PCR conditions were as follows: initial denaturation at $94^{\circ} \mathrm{C}$ for 3 minutes and 35 cycles consisting of 1 minute at $94^{\circ} \mathrm{C}$, 1 minute at $56^{\circ} \mathrm{C}$, and 2 minutes at $72^{\circ} \mathrm{C}$, plus an additional cycle of 7 minutes at $72^{\circ} \mathrm{C}$ for chain elongation.

The resulting PCR fragments using the nucleic acids isolated from the cellular phase as the templates were labeled as Sample Group 1 (\#1-9). The nucleic acids isolated from the liquid phases were subjected to reverse transcription first, then subjected to regular PCR reactions, resulting Sample Group 2 (\#11-19). For Sample Group 3, the nucleic acids isolated from the liquid phases were directly subjected to PCR reactions, resulting samples (\#21-29).

\section{PCR-Based Denaturing Gradient Gel Electrophoresis (DGGE) Assay}

A set of $16 \mathrm{~S}$ rDNA universal primers, BAC1 and BAC2 [24] was used to generate PCR product for DGGE analysis. A 40-nucleotide GC-clamp was added to the 5' end of BAC1 $[25,26]$. BAC1-GC (5-CGCCCGCCGCGCCCCGCGCCC GTCCCGCCGCCCCCGCCCGCCTACGGG-AGGCAGCA G-3') corresponds to nucleotide position 341 in the $E$. coli sequence [24], and BAC2 (5'-GGACTACCAGGGTATCT AATCC-3') corresponds to position 730 in the E. coli sequence (EF418614). PCR reactions were performed using the same condition as described above. The PCR products were evaluated by electrophoresis in $1.0 \%$ agarose gels run at $100 \mathrm{~V}$ for 60 minutes, and the size of all amplicons (300 bp) was confirmed according to a standard control described in Li et al. [27].

$20 \mu \mathrm{l}$ of each PCR-amplified product was loaded on the DGGE gel and was separated with the Bio-Rad DCode System (Bio-Rad, Hercules, CA). The same system was used for all DGGE experiments of this study. A 30\% to $70 \%$ linear DNA denaturing gradient $(100 \%$ denaturant is equi- valent to $7 \mathrm{M} / 1$ of urea and $40 \%$ deionized formamide) was formed in $8 \%(\mathrm{w} / \mathrm{v})$ polyacrylamide gels. PCR products were directly loaded in each lane, and electrophoresis was performed at a constant $60 \mathrm{~V}$ at $58^{\circ} \mathrm{C}$ for 16 hours in $1 \times$ TrisAcetate-EDTA (TAE) buffer $(\mathrm{pH}, 8.5)$. After electrophoresis, the gels were rinsed and stained for 15 minutes in water containing $0.5 \mu \mathrm{g} / \mathrm{ml}$ of ethidium bromide followed by 15 minutes of destaining in water. DGGE images were digitally captured and recorded with the AlphaImager 3300 System (Alpha Innotech Corporation, San Leandro, CA).

\section{Analysis of Microbial Profiles by DGGE}

DGGE gel images were converted and transferred into a microbial profile database with Fingerprinting II Informatix $^{\mathrm{TM}}$ Software (Bio-Rad). Each gel was normalized according to the species-specific DGGE standard markers; the background was subtracted with mathematical algorithms according to the spectral analysis of an overall densitometric curve. A $1.0 \%$ minimal profiling setting was used for band search for all DGGE gels. Levels of similarity between the fingerprints were calculated according to the Dice coefficient; the microbial compositions were assessed by measuring the total number of detected bands in all DGGE gels. The differences in the DGGE fingerprinting profiles of PCRamplified 16S rDNA segments were compared among the three sample groups. Analysis of variance (ANOVA) and Pearson Correlation were used for statistical analyses using SPSS 13.0 programs (Statistical Package for the Social Sciences, version 13.0, SSPS Inc, Chicago, IL). All $P$ values less than 0.05 were 2 -tailed.

\section{Random Cloning of PCR Products and Sequencing}

PCR products $(300 \mathrm{bp})$ generated from the reverse transcription reaction mixture of the liquid phase nuclei acids were cloned into $\mathrm{pCR}^{\circledR} 2.1-$ Topo $^{\circledR}$ (Invitrogen) according to the procedure of manufacturer's recommendation. Forty positive clones were randomly selected for sequencing. Sequence reactions were performed in the UCLA sequence facility using the primer BAC2. The sequences were used for BLAST search.

\section{RESULTS}

\section{Detection of Bacterial 16S rRNA and rDNA in Cellular and Liquid Phases of Saliva}

As described in Materials and Methods, sample group 1 (\#1-9) contains 16S rDNA from the cellular phase, sample group 2 (\#11-19) contains both 16S rDNA and rRNA from the liquid phase, and sample group 3 (\#21-29) contains $16 \mathrm{~S}$ rDNA from the liquid phase. It is worthwhile to mention that samples ending with the same digital number (such as 1,11 and 21) are from the same subject. The PCR products of the expected size were detected from all samples from all sample groups, indicating that bacterial $16 \mathrm{~S}$ rDNA/rRNA molecules not only existed in cellular phase, but also in liquid phase of saliva.

\section{DGGE Analysis of the Diverse $16 S$ rRNA/rDNA Species Present in Saliva}

We adapted the DGGE technique for profiling the $16 \mathrm{~S}$ rRNA/rDNA species present in the cell-free phase of saliva, in comparison with $16 \mathrm{~S}$ rDNA composition in the cellular 
phase of saliva. A $16 \mathrm{~S}$ specific primer pair (BAC1 and BAC2) with a 40-nucleotide GC-clamp (see Materials and Methods) was used to create PCR products within the same sample groups as described above. The DGGE analysis of these PCR products is shown in Fig. (1). While some bands are present in all three sample groups, there are clear differences between three groups as well.

We performed detailed analysis of these DGGE gels, using Fingerprinting II Informatix ${ }^{\mathrm{TM}}$ Software (Bio-Rad). A total of 91 distinct bands were detected. 57 bands (62.6\%) were presented in all three sample groups. As shown in Fig. (1), the cellular phase contains the most abundant 16S rDNA amplicons, the mean detectable bands in DGGE was $31 \pm 1.6$ (SD). The liquid phase of saliva contains both detectable 16S rDNA and 16S rRNA (comparing the PCR amplicon profiles of the RT and no-RT samples from the same individual, i.e. $\# 11$ and \#21). The mean detectable bands were $23.1 \pm 2.3$ (SD) for sample group 2 and $24.4 \pm 6.9$ (SD) for sample group 3. The difference between the abundance of $16 \mathrm{~S}$ amplicons among the three sample groups was statistically significant $(\mathrm{p}=0.007$, ANOVA). The similarities of DGGE profiles were $49.5 \%$ and $50.1 \%$ between group 1 and group 2 and group 1 and group 3, respectively. The similarity of DGGE profile was slightly higher $(54.1 \%)$ in comparison of group 2 with group 3 . Interestingly, there was a significant correlation $(P<0.001$, Pearson Correlation $=0.822)$ in the similarities between the RT and no-RT PCR amplicons of the cell-free phase DGGE profiles compared to that of the cellular phase.

\section{Identification of the $16 \mathrm{~S}$ rRNA/rDNA Species in the Cell- Free Phase of Saliva}

To further characterize the $16 \mathrm{~S}$ rRNA/rDNA species in saliva, over $100 \mathrm{PCR}$ products of $300 \mathrm{bp}$ from the liquid phase samples were randomly cloned. Forty positive clones were randomly selected among these clones for further sequence analysis. By comparing the sequences with known $16 \mathrm{~S}$ rRNA/rDNA sequences in the GenBank, we assigned the sequences to 15 operational taxonomic unit (OTU) groups. With $>99 \%$ sequence similarity as the cutoff value, we listed the closest representative for each OTU group in Table 1.

\section{DISCUSSION}

Despite the vast information known about the bacteria from whole saliva, little is known about the liquid phase of saliva with respect to the oral microbiota. Although it is known that the cell-free phase of human saliva contains viral and human RNAs [19-21], the presence of bacterial $16 \mathrm{~S}$ rRNA and rDNA in the liquid phase of saliva has not been looked at before. By using a pair of $16 \mathrm{~S}$ rDNA primers universal to most eubacteria, we showed in this study that both bacterial rRNA and rDNA exist in the liquid phase of saliva.

In this study, we applied DGGE technique to study the pattern of rRNA/rDNA in liquid phase and cellular phase of saliva. DGGE has been one of the common tools routinely used for microbial diversity and population dynamics studies in a variety of ecosystems [28]. This technique has been successfully applied in the study of microbial profiles within the oral cavity to characterize eubacterial $16 \mathrm{~S}$ rDNA fingerprints of human saliva and dental plaque microcosm biofilms grown in the multi-plaque artificial mouth [29] and to correlate the diversity of the oral microbial population and active dental caries [27]. The technique is based on polymorphism of the $16 \mathrm{~S}$ DNA variable regions among different bacteria and enables microbial community profiling assessments that do not rely on bacterial culturing. In general, a 300-500 base pair (bp) DNA fragment from the $16 \mathrm{~S}$ rDNA region is amplified by PCR along with a 40-bp GC clamp incorporated at the 5' end of one of the PCR primers to prevent total denaturation of the PCR product. The PCR product is then subjected to denaturant (urea) gradient gel electrophoresis

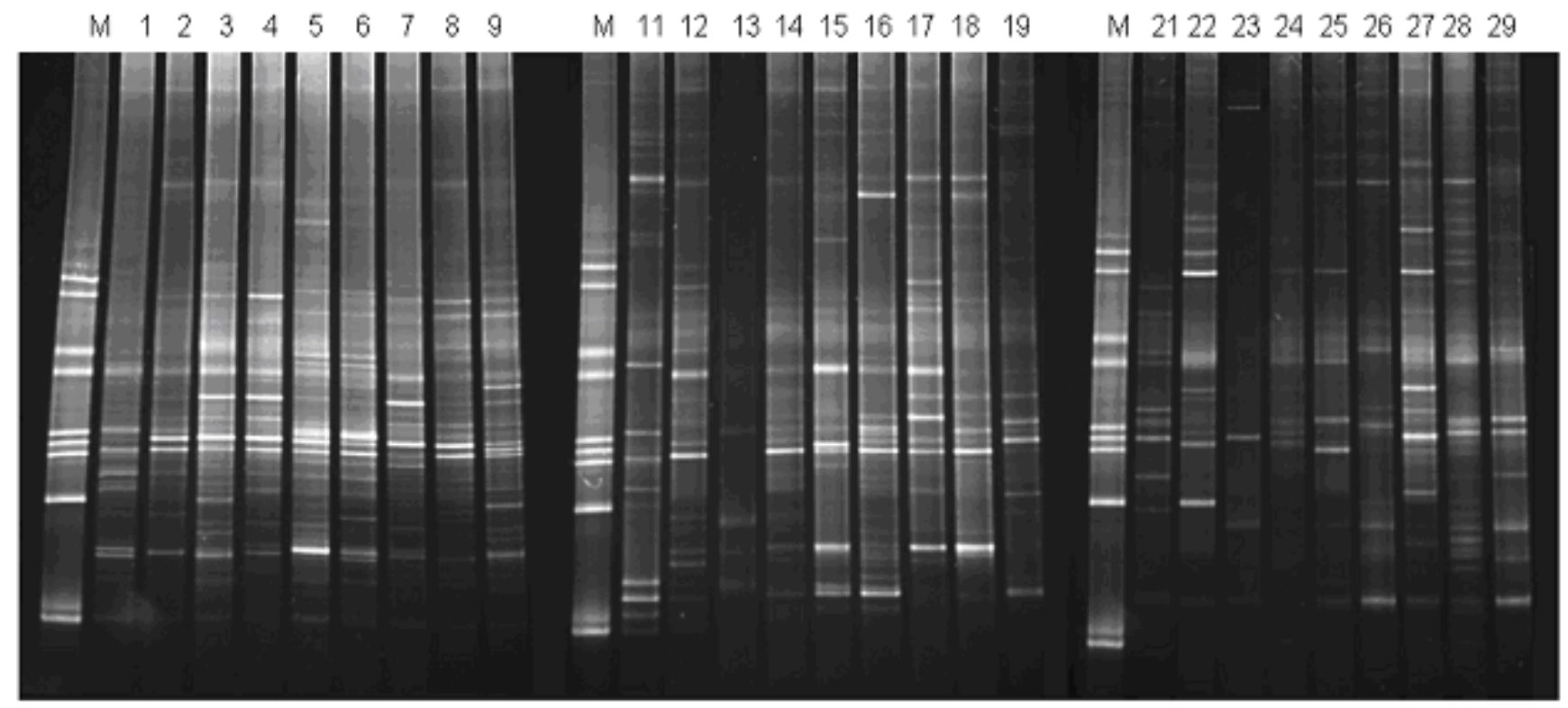

Fig. (1). DGGE analysis of 16S rDNA/rRNA in the cellular and liquid phases of saliva. M, species-specific DGGE standard markers (21); sample \#1-9 (sample group 1), 16S rDNA from cellular phase of saliva; sample \#11-19 (sample group 2), 16S rDNA/rRNA from liquid phase of saliva; sample \#21-29 (sample group 3), 16S rDNA from liquid phase of saliva. See Materials and Methods for experimental procedures and the description of the sample groups and analysis results. 
Table 1. 16S rDNA Sequences Identified from Liquid Phase of Saliva

\begin{tabular}{|c|c|c|c|}
\hline Operational Taxonomic Units & Closest Relative & $\%$ Sequence Similarity & Accession no. \\
\hline O-1 & Uncultured Actinomyces sp. & 100 & AF385522 \\
\hline O-3 & Uncultured Bacteroidetes & 100 & X85208 \\
\hline $\mathrm{O}-4$ & Diaphorobacter nitroreducens & 99 & AB076856 \\
\hline O-6 & Oribacterium sinus & 99 & AY323228 \\
\hline O-7 & Uncultured Prevotella sp. & 100 & AY684414 \\
\hline O-8 & Uncultured Veillonella sp. & 99 & AF366266 \\
\hline $\mathrm{O}-12$ & Streptococcus oralis & 100 & AY485602 \\
\hline O-13 & Uncultured Streptococcus dysagalactiae & 99 & AF371509 \\
\hline O-14 & Streptococcus thermophilus & 99 & СР000024 \\
\hline O-15 & Streptococcus mitis & 100 & DQ232534 \\
\hline
\end{tabular}

(DGGE). During electrophoresis, different 16S rDNA species are separated based on their sequence compositions. In this study, our DGGE analysis results demonstrate that each individual has his/her unique pattern of rRNA/rDNA species. Further analysis of pattern recognition using our DGGE results reveals that there was a significant correlation in the 16S rDNA amplicons detected between the cellular and liquid phases of saliva within each individual, indicating its possible application in monitoring microbial profile in oral cavity [30, 31]. However, there were differences between $16 \mathrm{~S}$ rDNA amplicons detected in the cellular and liquid phase of saliva. For example, there is a high-molecular weight band present in samples 16 and 26 (derived from the liquid phase of saliva) that appears to be absent in sample 6 (derived from the cellular phase) (Fig. 1). This indicated that the $16 \mathrm{~S}$ rDNA amplicons detected in the liquid phase of saliva is not necessary the fragment of $16 \mathrm{~S}$ rDNA in cellular phase of saliva.

In this study, we employed the PCR-cloning-sequencing technique to analyze the $16 \mathrm{~S}$ rRNA/rDNA in the liquid phase of saliva. The advantage of this method is that it includes both cultivable and uncultivable bacteria, allowing the complete analysis of complex bacterial communities. It is estimated that only about $50 \%$ of bacterial species in the oral microbiota are cultivable [32]. It is only with the advent of molecular biology that techniques have become available for studying mixed bacterial communities in their entirety, without the biases of culture [32]. Applying this method, a substantial number of novel taxa have been identified in molecular studies of gingivitis [33] and periodontitis [34]. Our analysis of $16 \mathrm{~S}$ rRNA in liquid phase of saliva indicated that about $50 \%$ of $16 \mathrm{~S}$ rRNA in cell-free phase of saliva is from uncultivable bacterial species, consistent with previous estimate. It is interesting to note some species found in this study were first identified from other biological niches or from the environment. For example, AY684414 was originally isolated from intestinal flora; AF523025 was first discovered from a DNA sample derived from mineral water; and AB098612 was identified from a DNA sample derived from petroleum. At this point, we do not know whether these rRNA/rDNA molecules are derived from the bacteria in normal oral microbial flora or the bacteria within the foods or water taken by the study subjects.

In this study, we identified some oral streptococcal $16 \mathrm{~S}$ rRNA/rDNA in the liquid phase of saliva (Table 1). This raises the possibility that other oral streptococcal genes may be represented in saliva. In vitro transformation of oral streptococcal antibiotic-resistance genes into Streptococcus pneumoniae has been demonstrated [35], as has transformation of an oral streptococcus in human saliva [36]. Our findings suggest that the oral streptococcal antibiotic resistance may spread via saliva.

The findings from this study that abundant bacterial DNA and RNA exist in the liquid phase of saliva opens a new possibility for oral pathogen detection since the liquid phase of saliva could be directly used for $16 \mathrm{~S}$ rDNA/rRNA detection without lysis of bacterial cells. This will not only reduce the sample processing procedure and consequently time, but also minimize the sampling processing variability. While the findings described in this study creates a great new opportunity for oral pathogen detection, much more work yet need to be done to validate the concept that $16 \mathrm{~S}$ rDNA/ rRNA in the liquid phase of saliva could be indeed applicable for the diagnosis of oral microbial infectious diseases. 


\section{ACKNOWLEDGEMENTS}

This work was supported in part by NIH grants U01DE15018 (D.Wong), R01-DE014757 (F. Qi), R03-DE015706 (Y. Li) and Delta Dental grant (W. Shi).

\section{REFERENCES}

[1] Marsh PD. Microbiologic aspects of dental plaque and dental caries. Dent Clin North Am 1999; 43(4): 599-614, v-vi

[2] Socransky SS, Haffajee AD, Cugini MA, Smith C, Kent RL, Jr. Microbial complexes in subgingival plaque. J Clin Periodontol 1998; 25(2): 134-44

[3] Marsh PD. Are dental diseases examples of ecological catastrophes? Microbiology 2003; 149(Pt 2): 279-94.

[4] Marsh PD. Role of the oral microflora in health. Microb Ecol Health Dis 2000; 12: 130-37.

[5] Bowden GH. Microbiology of root surface caries in humans. J Dent Res 1990; 69(5): 1205-10.

[6] Tanzer JM, Livingston J, Thompson AM. The microbiology of primary dental caries in humans. J Dent Educ 2001; 65(10): 102837.

[7] van Houte J. Microbiological predictors of caries risk. Adv Dent Res 1993; 7(2): 87-96.

[8] Hiratsuka K, Yoshida W, Hayakawa M, Takiguchi H, Abiko Y. Polymerase chain reaction and an outer membrane protein gene probe for the detection of Porphyromonas gingivalis. FEMS Microbiol Lett 1996; 138(2-3): 167-72.

[9] Igarashi T, Yamamoto A, Goto N. PCR for detection and identification of Streptococcus sobrinus. J Med Microbiol 2000; 49(12): 1069-74.

[10] Morillo JM, Lau L, Sanz M, Herrera D, Silva A. Quantitative realtime PCR based on single copy gene sequence for detection of Actinobacillus actinomycetemcomitans and Porphyromonas gingivalis. J Periodontal Res 2003; 38(5): 518-24.

[11] Igarashi T, Yamamoto A, Goto N. Direct detection of streptococcus mutans in human dental plaque by polymerase chain reaction. Oral Microbiol Immunol 1996; 11(5): 294-8

[12] Matto J, Saarela M, Alaluusua S, Oja V, Jousimies-Somer H, Asikainen S. Detection of porphyromonas gingivalis from saliva by PCR by using a simple sample-processing method. J Clin Microbiol 1998; 36(1): 157-60

[13] Sato T, Matsuyama J, Takahashi N, et al. Differentiation of oral Actinomyces species by $16 \mathrm{~S}$ ribosomal DNA polymerase chain reaction-restriction fragment length polymorphism. Arch Oral Biol 1998; 43(3): 247-52.

[14] Price RR, Viscount HB, Stanley MC, Leung KP. Targeted profiling of oral bacteria in human saliva and in vitro biofilms with quantitative real-time PCR. Biofouling 2007; 23: 203-13.

[15] Socransky SS, Haffajee AD, Smith C, et al. Use of checkerboard DNA-DNA hybridization to study complex microbial ecosystems. Oral Microbiol Immunol 2004; 19(6): 352-62.

[16] Socransky SS, Smith C, Martin L, Paster BJ, Dewhirst FE, Levin AE. Checkerboard DNA-DNA hybridization. Biotechniques 1994; 17(4): 788-92.

[17] Wall-Manning GM, Sissons CH, Anderson SA, Lee M. Checkerboard DNA-DNA hybridisation technology focused on the analysis of Gram-positive cariogenic bacteria. J Microbiol Methods 2002; 51(3): 301-11

[18] Moraes SR, Siqueira JF, Jr., Colombo AP, Rjcas I, de S, Domingues R. Comparison of the effectiveness of bacterial culture, $16 \mathrm{~S}$ rDNA directed polymerase chain reaction, and checkerboard DNA-dNA hybridization for detection of fusobacterium nucleatum in endodontic infections. J Endod 2002; 28(2): 86-9.
[19] Kakizawa J, Ushijima H, Oka S, Ikeda Y, Schroder HC, Muller WE. Detection of human immunodeficiency virus-1 DNA, RNA and antibody, and occult blood in inactivated saliva: availability of the filter paper disk method. Acta Paediatr Jpn 1996; 38(3): 218-23.

[20] Biasi D, Colombari R, Achille A, et al. HCV RNA detection in parotid gland biopsy in a patient with chronic hepatitis $\mathrm{C}$ virus liver disease. Acta Gastroenterol Belg 1995; 58(5-6): 465-9.

[21] Li Y, Zhou X, St John MA, Wong DT. RNA profiling of cell-free saliva using microarray technology. J Dent Res 2004; 83(3): 199203.

[22] Gau JJ, Lan EH, Dunn B, Ho CM, Woo JC. A MEMS based amperometric detector for E. coli bacteria using self-assembled monolayers. Biosens Bioelectron 2001; 16(9-12): 745-55.

[23] Lopez I, Ruiz-Larrea F, Cocolin L, et al. Design and evaluation of PCR primers for analysis of bacterial populations in wine by denaturing gradient gel electrophoresis. Appl Environ Microbiol 2003; 69(11): 6801-7.

[24] Fujimoto C, Maeda H, Kokeguchi S, et al. Application of denaturing gradient gel electrophoresis (DGGE) to the analysis of microbial communities of subgingival plaque. J Periodontal Res 2003; 38(4): 440-5.

[25] Sheffield VC, Cox DR, Lerman LS, Myers RM. Attachment of a 40-base-pair G + C-rich sequence (GC-clamp) to genomic DNA fragments by the polymerase chain reaction results in improved detection of single-base changes. Proc Natl Acad Sci USA 1989; 86(1): 232-6.

[26] Rupf S, Merte K, Eschrich K. Quantification of bacteria in oral samples by competitive polymerase chain reaction. J Dent Res 1999; 78(4): 850-6.

[27] Li Y, Ku CY, Xu J, Saxena D, Caufield PW. Survey of oral microbial diversity using PCR-based denaturing gradient gel electrophoresis. J Dent Res 2005; 84(6): 559-64.

[28] Muyzer G. DGGE/TGGE a method for identifying genes from natural ecosystems. Curr Opin Microbiol 1999; 2(3): 317-22.

[29] Rasiah IA, Wong L, Anderson SA, Sissons CH. Variation in bacterial DGGE patterns from human saliva: over time, between individuals and in corresponding dental plaque microcosms. Arch Oral Biol 2005; 50(9): 779-87.

[30] Eger T, Zoller L, Muller HP, Hoffmann S, Lobinsky D. Potential diagnostic value of sampling oral mucosal surfaces for Actinobacillus actinomycetemcomitans in young adults. Eur J Oral Sci 1996; 104(2 (Pt 1)): 112-7.

[31] Llena-Puy MC, Montanana-Llorens C, Forner-Navarro L. Cariogenic oral flora and its relation to dental caries. ASDC J Dent Child 2000; 67(1): 42-6, 9 .

[32] Wade W. Unculturable bacteria--the uncharacterized organisms that cause oral infections. J R Soc Med 2002; 95(2): 81-3.

[33] Kroes I, Lepp PW, Relman DA. Bacterial diversity within the human subgingival crevice. Proc Natl Acad Sci USA 1999; 96(25): 14547-52.

[34] Sakamoto M, Umeda M, Ishikawa I, Benno Y. Comparison of the oral bacterial flora in saliva from a healthy subject and two periodontitis patients by sequence analysis of $16 \mathrm{~S}$ rDNA libraries. Microbiol Immunol 2000; 44(8): 643-52.

[35] Hakenbeck R, Konig A, Kern I, et al. Acquisition of five high-Mr penicillin-binding protein variants during transfer of high-level beta-lactam resistance from Streptococcus mitis to Streptococcus pneumoniae. J Bacteriol 1998; 180(7): 1831-40.

[36] Mercer DK, Scott KP, Melville CM, Glover LA, Flint HJ. Transformation of an oral bacterium via chromosomal integration of free DNA in the presence of human saliva. FEMS Microbiol Lett 2001; 200(2): 163-7. 